Check for updates

Cite this: RSC Adv., 2017, 7, 48253

Received 19th August 2017

Accepted 9th October 2017

DOI: 10.1039/c7ra09189c

rsc.li/rsc-advances

\section{Development of low temperature stoichiometric solution combustion derived transparent conductive ternary zinc tin co-doped indium oxide electrodes $\uparrow$}

\author{
Pavan Pujar, ${ }^{\text {ac }}$ Srinivas Gandla, ${ }^{c}$ Mukesh Singh, ${ }^{c}$ Bikesh Gupta, ${ }^{a}$ Kartick Tarafder, ${ }^{b}$ \\ Dipti Gupta, ${ }^{c}$ Yong-Young Noh iD d and Saumen Mandal (D)*a
}

\begin{abstract}
Here, the development of transparent conductive zinc tin co-doped indium oxide (IZTO: $\ln _{1.4} \mathrm{Sn}_{0.3} \mathrm{Zn}_{0.3} \mathrm{O}_{3}$ ) ternary electrodes is addressed through low temperature solution combustion processing. Optimization of fuel to oxidizer ratio offers low temperature $\left(\sim 130^{\circ} \mathrm{C}\right)$ of combustion with balanced redox reaction. The thin films of IZTO annealed at different temperatures showed a decreasing trend in the resistivity with a fixed order of $10^{-2} \Omega \mathrm{cm}$ and the film with a highest Hall mobility of $5.92 \mathrm{~cm}^{2} \mathrm{~V}^{-1} \mathrm{~s}^{-1}$ resulted at $400{ }^{\circ} \mathrm{C}$. All the films with different temperatures of annealing were smooth (rms $\leq 2.42 \mathrm{~nm}$ ) in nature and the IZTO film annealed at $200{ }^{\circ} \mathrm{C}$ is $83 \%$ transparent in the visible spectra. The effective band gap of $0.9 \mathrm{eV}$ determined from first-principles density functional theory gives clear evidence for the conducting nature of IZTO. The thin film transistor fabricated with IZTO as a gate electrode with poly(methyl methacrylate) and pentacene as the dielectric and channel material, respectively, exhibited a saturation mobility of $0.44 \mathrm{~cm}^{2} \mathrm{~V}^{-1} \mathrm{~s}^{-1}$ and $I_{\mathrm{on}} / I_{\text {off }}$ ratio of $10^{3}$. Further, the printability of the IZTO combustible precursor is established which resulted in anti-edge deposition of the printed feature.
\end{abstract}

\section{Introduction}

The scientific interest in the field of transparent conducting oxides (TCOs) is increasing continuously because of the coexistence of transparency, conductivity and solution processability offered by these materials in optoelectronic devices; such as electrodes for flat panel displays, ${ }^{1-3}$ anodes for organic light emitting diodes, ${ }^{4-6}$ touch panels, ${ }^{7}$ and solar cells. ${ }^{8,9}$ Indium based binary (tin doped indium oxide (ITO), ${ }^{\mathbf{1 0}, 11}$ zinc doped indium oxide (IZO) ${ }^{12,13}$ ) and ternary (zinc and tin co-doped indium oxide $(\text { IZTO })^{14,15}$ ) oxides are a few such widely accepted TCOs. Co-doping gives a larger window of composition and shows conductivity of one order less than ITO; ${ }^{16}$ this helps in tailoring the properties of IZTO for particular applications. As evidence; the IZTO film can be used as transparent conductor as well as transparent semiconductor. The Gibb's triangle at $1275{ }^{\circ} \mathrm{C}$ focused on two solid solutions of IZTO; ${ }^{1}$ which can be used as a TCO; namely zinc and

${ }^{a}$ Department of Metallurgical and Materials Engineering, National Institute of Technology Karnataka (NITK), Surathkal-575025, India. E-mail: smandal@nitk.edu. in

${ }^{b}$ Department of Physics, National Institute of Technology Karnataka (NITK), Surathkal575025, India

'Plastic Electronics and Energy Laboratory, Department of Metallurgical Engineering and Materials Science, Indian Institute of Technology Bombay, Powai 400 076, India ${ }^{d}$ Department of Energy \& Materials Engineering, Dongguk University, 30, Pildong-ro 1gil, Jung-gu, Seoul, 04620, Republic of Korea

† Electronic supplementary information (ESI) available. See DOI: 10.1039/c7ra09189c tin co-doped indium oxide bixbyite: $\operatorname{In}_{(2-2 x)} \mathrm{Zn}_{x} \mathrm{Sn}_{x} \mathrm{O}_{3}$ where $x \leq$ 0.4 and indium substituted $\mathrm{Zn}_{2} \mathrm{SnO}_{4}$ (zinc stannate spinel): $\mathrm{Zn}_{2-x} \mathrm{Sn}_{1-x} \mathrm{In}_{2 x} \mathrm{O}_{4}$ where $x=0-0.45$. On the other hand; $\mathrm{Zn}_{(9-2 x)} \operatorname{In}_{x} \operatorname{Sn}_{x} \mathrm{O}_{(9+1.5 x)}(1 \leq x \leq 4)$ and $\mathrm{ZnIn}_{(8-x)} \operatorname{Sn}_{x} \mathrm{O}_{(13+0.5 x)}(1 \leq x$ $\leq 7)$ are semiconducting in nature. ${ }^{17}$ In addition to the advantages of IZTO mentioned above, it is cost effective and $60 \%$ of indium usage can be reduced $\mathbf{1 1 0}^{\mathbf{1 1 8 , 1 9}}$ compared to ITO. The reason for unusual combination of properties (transparency and conductivity) of doped oxides is extent of doping and crystal structure. ${ }^{1}$ Indium oxide has two polymorphs namely; (a) a cubic bixbyite type $\left(\mathrm{c}-\mathrm{In}_{2} \mathrm{O}_{3}\right)$ with $a=10.116 \AA, Z=16$ is stable under atmospheric pressure conditions. ${ }^{20}$ (b) Corundum type (rh$\left.\mathrm{In}_{2} \mathrm{O}_{3}\right)^{20,21}$ with $a=5.491 \AA, c=14.526 \AA, Z=6$ is metastable under ambient atmospheric conditions; ${ }^{22}$ which can be stabilized by (i) in quasi 1D nanostructures, (ii) in the sol-gel synthesized $\mathrm{In}_{2} \mathrm{O}_{3}$ and (iii) $\mathrm{Sn}^{4+} / \mathrm{Fe}^{3+} / \mathrm{N}^{3-}$ doped $\mathrm{In}_{2} \mathrm{O}_{3}$. Further, the optical band gap of oxides varies from 3 to $4 \mathrm{eV}$, mention a few; ITO: $\sim 4.0 \mathrm{eV},{ }^{23} \mathrm{TiO}_{2}$ : $3.2 \mathrm{eV},{ }^{24} \mathrm{ZnO}: 3.36 \mathrm{eV},{ }^{25}$ IZTO: 3.0 to $3.5 \mathrm{eV}$ (ref. 8) in the form of thin films; although optical band gap is high, ITO and IZTO exhibit high conductivity. ${ }^{8,23}$

Over the years thin films of TCOs have been grown using different techniques, such as sputtering, pulse laser deposition etc. Although several evaporation techniques are available; but have got limitations as far as cost, production rate, large scale and mass production are concerned; these problems can be addressed by solution processing techniques. There are basically two routes for the solution processed oxide films, namely; the precursor solution containing respective metal cations can 
be coated using techniques such as spin coating, ${ }^{26,27}$ dip coating, ${ }^{28,29}$ spray coating; ${ }^{30}$ and another route, where oxide nano particles/nano structures (wires etc.) can be dispersed into a solvent and the resulting dispersant can be utilized for the fabrication of thin film using different coating ${ }^{31,32}$ and printing $^{33}$ methods. Kim et. al., reported solution processed amorphous IZTO thin film as an active layer in thin film transistors (TFT); nature of the film was confirmed through transmission electron microscopy. ${ }^{\mathbf{1 7}}$ Here we emphasize on the synthesis of IZTO powders using self-propagating solution combustion technique and spin coated combustible precursors to fabricate IZTO thin films.

The solution combustion technique uses metal precursors along with fuel and oxidizers. Generally nitrates employed as oxidizers and hydrocarbons as fuel. It has been reported that bulk materials such as carbides, borides, silicides, phosphides, hydrides, chalcogenides ${ }^{34}$ and binary oxides ${ }^{35}$ can be synthesized via solution combustion technique; here we extend the technique to conductive complex ternary oxides. The unique advantage of the combustion processing is that the stoichiometry of the product can be tailored based on the amount of precursors used. In addition, the process is simple and fast.

In this study, we address solution combustion synthesis of ternary complex oxide system $\mathrm{In}_{1.4} \mathrm{Zn}_{0.3} \mathrm{Sn}_{0.3} \mathrm{O}_{3}$, where acetylacetone $\left(\mathrm{C}_{5} \mathrm{H}_{8} \mathrm{O}_{2}\right)$ serves as fuel. In the process, oxidation of cation of nitrates (oxidizer; $\mathrm{O}$ ) occurs along with the reduction reaction of fuel (F); thus proper selection of $\mathrm{F}$ and $\mathrm{O}$ becomes crucial. Here we report IZTO synthesized using different fuel to oxidizer ratios (F:O). A detailed theoretical study with X-ray diffraction helped us to predict the unit cell and band structure of IZTO. Finally, predicted band structure is developed using density functional theory (DFT) which is correlated with the optical band gap from absorption spectroscopy. Also, the IZTO film fabricated further utilized as transparent electrode and a TFT constituting of which is fabricated in order to show applicability of present solution combustion derived IZTO. To address printability of the combustible precursor a line feature is printed and confirmed its anti-edge deposit nature.

\section{Experimental section}

\subsection{Preparation and characterization of combustible precursors}

Solution containing $500 \mathrm{mg}$ of indium nitrate $\left(\operatorname{In}\left(\mathrm{NO}_{3}\right)_{3}\right.$, Sigma Aldrich), $92.7 \mathrm{mg}$ of tin chloride ( $\mathrm{SnCl}_{4}$, Sigma Aldrich) and $67.4 \mathrm{mg}$ zinc nitrate $\left(\mathrm{Zn}\left(\mathrm{NO}_{3}\right)_{2}\right.$, Tarson Chemicals, India) in 2methoxyethanol (2-ME, Tarson Chemicals, India), were prepared. Addition of the fuel - acetylacetone $\left(\mathrm{C}_{5} \mathrm{H}_{8} \mathrm{O}_{2}\right.$, Tarson Chemicals, India) was designed based on the balanced chemical equation (eqn (1)). In order to analyze the effect of excess and lean redox mixtures; two more solutions with varying $\mathrm{F}$ : $\mathrm{O}$ were prepared; quantity of fuel in each case was decided based on the molar ratios of fuel and oxidizer (F : O). An optimum $\mathrm{F}: \mathrm{O}(=0.5$; obtained from balanced redox reaction, eqn (1)), fuel rich $(\mathrm{F}: \mathrm{O}=5)$ and fuel lean $(\mathrm{F}: \mathrm{O}=0.05)$ precursors were obtained by adding $100 \mu \mathrm{l}, 1000 \mu \mathrm{l}$ and $10 \mu \mathrm{l}$ of $\mathrm{C}_{5} \mathrm{H}_{8} \mathrm{O}_{2}$ respectively to solutions containing $18 \mathrm{ml}(0.2 \mathrm{M})$ of 2-ME. All three solutions were stirred for $72 \mathrm{~h}$ to make them clear and stable. Precursors (by keeping in vacuum oven at $40{ }^{\circ} \mathrm{C}$ for $8 \mathrm{~h}$ ) were utilized for the thermal analysis (heating rate $=$ $10{ }^{\circ} \mathrm{C} \mathrm{min}^{-1}$ ) using differential scanning calorimetry (DSC, NETZSCH-DSC-404F1) calibrated with pure indium (purity: 99.999\%). All three solutions were combusted on a hot plate and product-oxide powder was calcined at $600{ }^{\circ} \mathrm{C}$ for $2 \mathrm{~h}$. X-ray diffraction (XRD, JEOL-JPX 8) patterns were traced at a scanning rate of $1^{\circ} \mathrm{min}^{-1}$ for both calcined and as-combusted powder. Selected area electron diffraction (SAED) patterns were recorded for as-combusted powder using Transmission Electron Microscope (TEM, JEM-2100, JEOL) operated at $200 \mathrm{kV}$.

$$
\begin{aligned}
& 28 \mathrm{In}\left(\mathrm{NO}_{3}\right)_{3}+6 \mathrm{SnCl}_{4}+6 \mathrm{Zn}\left(\mathrm{NO}_{3}\right)_{2}+19 \mathrm{C}_{5} \mathrm{H}_{8} \mathrm{O}_{2} \rightarrow \\
& 2 \mathrm{In}_{14} \mathrm{Sn}_{3} \mathrm{Zn}_{3} \mathrm{O}_{30}+95 \mathrm{CO}_{2}+76 \mathrm{H}_{2} \mathrm{O}+48 \mathrm{~N}_{2}+12 \mathrm{Cl}_{2}
\end{aligned}
$$

\subsection{Thin film fabrication and characterization}

Solution with optimum F : O $(=0.5)$ is spin coated $(2000 \mathrm{rpm}$, $35 \mathrm{~s}$ ) on to the glass substrate (Corning 1737F: Sigma Aldrich) and annealed at different temperatures $\left(200{ }^{\circ} \mathrm{C}, 300{ }^{\circ} \mathrm{C}\right.$ and $400{ }^{\circ} \mathrm{C}$ ) on a hot plate for $30 \mathrm{~min}$; desired thickness is achieved by multi-coating utilizing $50 \mu \mathrm{l}$ of combustible precursors in each coat. The obtained thin film was characterized using UV visible spectroscopy (SHIMADZU, UV-3600), Atomic Force Microscopy (AFM, Park XE-100), Grazing Incidence Angle X-ray Diffraction (GIAXRD, RIGAKU-Japan) and X-ray photoelectron spectroscopy (XPS, model: PHI5000VersaProbeII). In order to know the carrier concentration $(N)$, Hall mobility $\left(\mu_{\mathrm{H}}\right)$ and resistivity $(\rho)$, Hall effect measurements were carried out for all three samples annealed at different temperatures.

\subsection{Fabrication and characterization of thin film transistor}

In order to reveal the efficacy of the IZTO film to be used as a conducting thin film a TFT with a bottom gate top contact architecture is fabricated on to a glass substrate with spin coated (1000 rpm, $30 \mathrm{~s}$ and annealed at $90{ }^{\circ} \mathrm{C}$ for $30 \mathrm{~min}$ ) commercial grade poly(methyl methacrylate) - PMMA (Microchem XR1541) as the dielectric layer followed by thermally deposited $50 \mathrm{~nm}$ pentacene as a channel layer. Finally gold contacts $(30 \mathrm{~nm})$ were evaporated thermally with a channel length $(L)$ of $100 \mu \mathrm{m}$ and channel width $(W) 1000 \mu \mathrm{m}$. The fabricated devices were characterized in ambient atmosphere in dark using semiconductor characterization system having a KEITHLEY-4200 source meter. The saturation mobility ( $\mu_{\text {sat }}$ ) of the TFT is calculated from eqn (2) and other characteristics such as $I_{\mathrm{on}}: I_{\mathrm{off}}$, threshold voltage $\left(V_{\mathrm{T}}\right)$ were determined from transfer characteristics. In order to measure capacitance, a device having a configuration metal/ insulator/metal, was fabricated on commercial ITO coated glass (ITO/PMMA/Au) using broadband dielectric spectrometer.

$$
\mu_{\mathrm{sat}}=\frac{\left(\frac{\mathrm{d} \sqrt{I_{\mathrm{D}}}}{\mathrm{d} V_{\mathrm{G}}}\right)^{2}}{\frac{1}{2} C_{\mathrm{i}} \frac{W}{L}}
$$

where, $I_{\mathrm{D}}$ is drain current and $C_{\mathrm{i}}$ is the capacitance per unit area. 


\subsection{Theoretical study of unit cell and band structure of IZTO}

To predict the unit cell of the zinc and tin co-doped $\operatorname{In}_{2} \mathrm{O}_{3}$, we have considered cubic $\operatorname{In}_{2} \mathrm{O}_{3}$ as the parent structure with space group $I a 3$ (number 199). Few indium atoms in the $\operatorname{In}_{2} \mathrm{O}_{3}$ unit cell were randomly chosen and replaced by tin and zinc atoms. Next we have performed first-principles DFT calculations on each predicted unit cell using Vienna $a b$ initio simulation package $\mathrm{e}^{36-38}$ which uses pseudopotentials and the projector augmented wave approach. We used the PerdewBurke-Ernzerhof generalized gradient approximation for treating the exchange-correlation potential. The onsite Coulomb interaction correction was taken into account by using GGA + U method. A sufficiently high-energy cutoff $(500 \mathrm{eV})$ was used in each calculation to obtain accurate results. In our simulations the forces on each of the atoms were calculated using the Hellmann-Feynman theorem, and were subsequently used to perform a conjugate gradient structural relaxation. The structural optimizations were continued until the forces on the atoms converged to less than $1 \mathrm{meV}^{-1}$. Finally, the total energy of optimized geometries was compared considering the optimized structure with minimum total energy for further electronic band structure investigation.

\subsection{Inkjet printing of IZTO combustible solution}

To show the printability of the combustible IZTO solution, line feature is printed (width $\sim 270 \mu \mathrm{m}$ ) using inkjet printer (MicroFab Technologies Inc.) having a nozzle of $60 \mu \mathrm{m}$ orifice diameter. Two number of passes were printed subsequently and annealed at $150{ }^{\circ} \mathrm{C}$ then slowly rising the annealing temperature to $200{ }^{\circ} \mathrm{C}$ and finally the film was annealed at $400{ }^{\circ} \mathrm{C}$ for $30 \mathrm{~min}$. The line profile of printed feature is traced by thickness profilometer (Dektak XT; make: Bruker).

\section{Results and discussion}

The stoichiometry $\left(\operatorname{In}_{2-2 x} \mathrm{Zn}_{x} \mathrm{Sn}_{x} \mathrm{O}_{3} ; x=0.3\right)$ selected in this study was adopted from the Gibb's triangle ${ }^{1}$ as shown in Fig. 1a; though the maximum solubility is upto 40 at $\%$ ( $x=0.4$, Fig. 1a), in order to avoid secondary non-conducting phases only 30 at $\%$ doping has been selected. Further, the schematic (Fig. 1b) guides the reader through both bulk-powder synthesis and thin

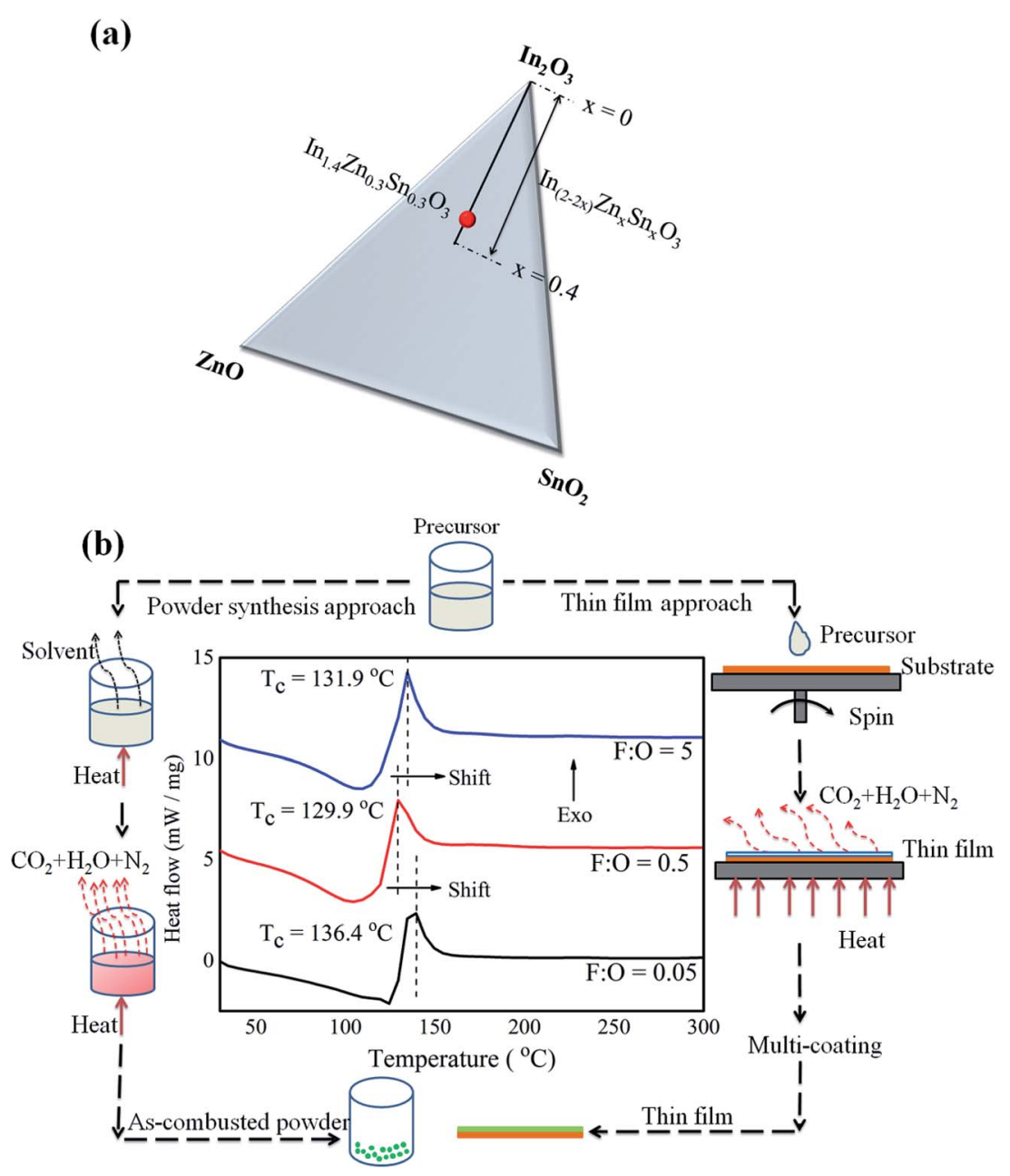

Fig. 1 (a) Gibb's triangle of $\mathrm{In}_{2} \mathrm{O}_{3}-\mathrm{ZnO}-\mathrm{SnO}_{2}$ ternary system showing stoichiometry of the present study. (b) Schematic of the processes employed and differential scanning calorimetric curves of precursors prepared with different $\mathrm{F}: \mathrm{O}$ ratios. 



Fig. 2 (a) XRD pattern of as-combusted powders with varying $F$ : $O$ ratios and TEM micrographs along with SAED patterns of powder with (b) $\mathrm{F}: \mathrm{O}=0.05$; (c) $\mathrm{F}: \mathrm{O}=5$; (d) and (e) $\mathrm{F}: \mathrm{O}=0.5$.

film fabrication methods employing same combustible precursors. The DSC thermogram of combustible precursors (Fig. 1b) with varying $\mathrm{F}: \mathrm{O}$ ratios shows endothermic peaks in all three cases at around $125{ }^{\circ} \mathrm{C}$ corresponds to solvent evaporation; which is noted to be boiling point of 2-ME. The exothermic response of DSC at $136.4{ }^{\circ} \mathrm{C}, 129.9^{\circ} \mathrm{C}$ and $131.9^{\circ} \mathrm{C}$ in case of $\mathrm{F}: \mathrm{O}=0.05,0.5$ and 5 respectively gives an evidence of combustion reaction. It is clear that the combustion temperature is low in case of balanced redox mixture. This confirms that, minimum temperature is required to initiate the reaction provided there should be an optimum mixture of combustible elements as depicted in the eqn (1); $129.9^{\circ} \mathrm{C}$ is the minimum temperature ever reported for combustion of indium based ternary oxides. Kim et. al. ${ }^{35}$ reported a combustion temperature of $200{ }^{\circ} \mathrm{C}$ for acetylacetone based unary systemindium oxide. With fuel lean $(\mathrm{F}: \mathrm{O}=0.05)$ and fuel rich $(\mathrm{F}: \mathrm{O}$ $=5$ ) mixtures the DSC exothermic shows right shift (Fig. 1b) confirming increase in combustion temperature. Commenting on the type of combustion; the combustion of optimum $\mathrm{F}: \mathrm{O}$ mixture shows clean burning of redox mixture but the fuel rich shows excessive fumes depicting burning of excess fuel. In addition, fuel lean mixture shows sudden flaming (ESI S1 $†$ ). These variants in burning are due to amounts of fuel and oxidizer present in the redox mixture..$^{39}$

As-combusted powders were subjected to X-ray diffraction studies (Fig. 2a), just by looking at the pattern it is difficult to confirm whether the powder is amorphous or crystalline especially in case of $\mathrm{F}: \mathrm{O}=0.5$ (Fig. 2a). In order to get a clear perspective; SAED patterns were recorded and found that fuel lean (Fig. 2b) and fuel rich (Fig. 2c) powders were crystalline in nature. But, in case of optimum redox mixture (Fig. $2 \mathrm{~d}$ and e) the powder was mixture of amorphous and crystalline phases. The degree of crystallinity is less prominent in case of $\mathrm{F}: \mathrm{O}=$ 0.5 ; thus no fringe pattern was observed (Fig. 2e). This may be due to amount of energy generated during combustion of precursors with balanced redox mixture. The heat energy may not be sufficient to make the powder complete crystalline; thus extra amount of energy needed for the complete crystallization. In addition, the colour of as-combusted powder in case of $\mathrm{F}: \mathrm{O}$ $=5$ is black; this may be due to retainment of unburnt excess carbon.

The as-combusted powders were further subjected to calcination for $2 \mathrm{~h}$ at $600{ }^{\circ} \mathrm{C}$; and XRD pattern (Fig. 3a) of calcined
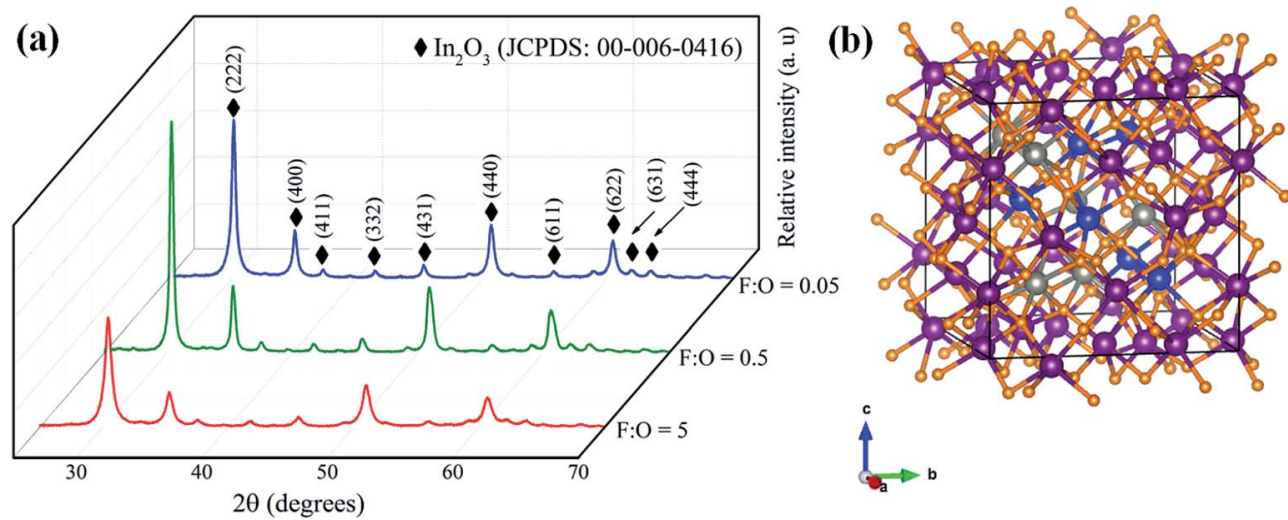

Fig. 3 (a) XRD patterns of calcined IZTO powders with different F : O ratios. (b) Unit cell of IZTO with blue - tin, purple - indium, grey - zinc and orange - oxygen. 
(a)

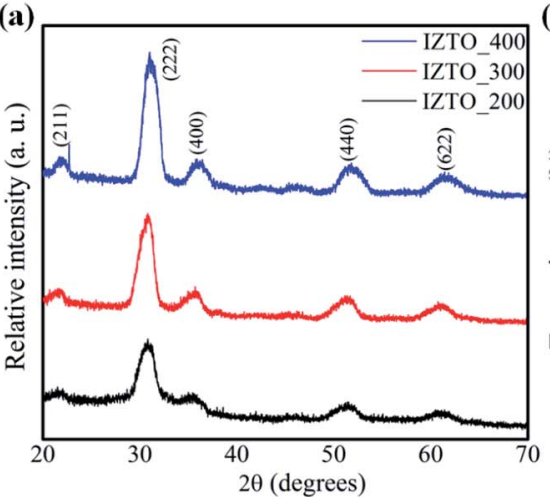

(b)

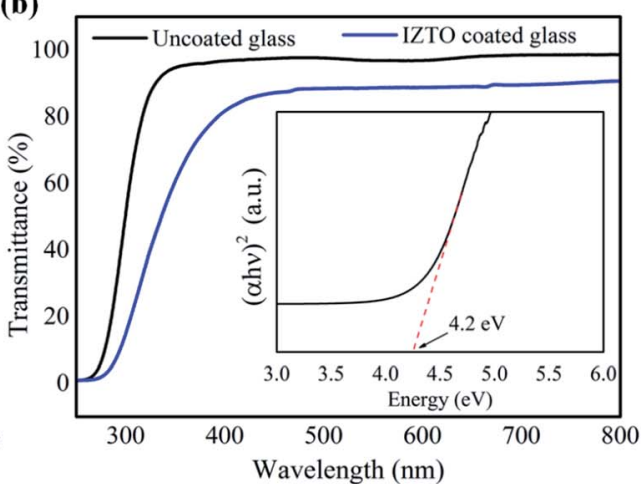

Fig. 4 (a) GIAXRD plots of spin coated IZTO films annealed at different temperatures (b) UV-visible spectroscopic result of IZTO film (annealed at $200{ }^{\circ} \mathrm{C}$ ) showing $83 \%$ transparency with optical and gap (inset).

powders show high degree of crystallinity with no secondary phases. The pattern perfectly matches with JCPDS: 00-006-0416 confirming the cubic bixbyite nature of the material. This implies, post doped structure retains original bixbyite of $\operatorname{In}_{2} \mathrm{O}_{3}$; which motivated us to develop unit cell of IZTO describing dopant positions using DFT (Fig. 3b).

Further, the precise lattice parameter of IZTO estimated using Nelson Riley function ${ }^{40}$ (for optimum F : $\mathrm{O}(=0.5)$ ) and compared with combustion derived $\operatorname{In}_{2} \mathrm{O}_{3}$ powder and found that there is slight increase $(10.14 \AA)$ in the value post doping compared to host $\operatorname{In}_{2} \mathrm{O}_{3}(10.11 \AA)$, though the dopants $\mathrm{Zn}^{2+}$ $(0.074 \mathrm{~nm})$ and $\mathrm{Sn}^{4+}(0.069 \mathrm{~nm})$ are of smaller size compared to $\mathrm{In}^{3+}(0.080 \mathrm{~nm})$. The reported lattice parameter of IZTO is around $9.99 \AA$ A which is much lower than the present value due to high temperature processing $\left(1275^{\circ} \mathrm{C}\right)$ with longer time $(24$ to $72 \mathrm{~h}) .{ }^{1}$ Whereas, in the present study calcination was carried out

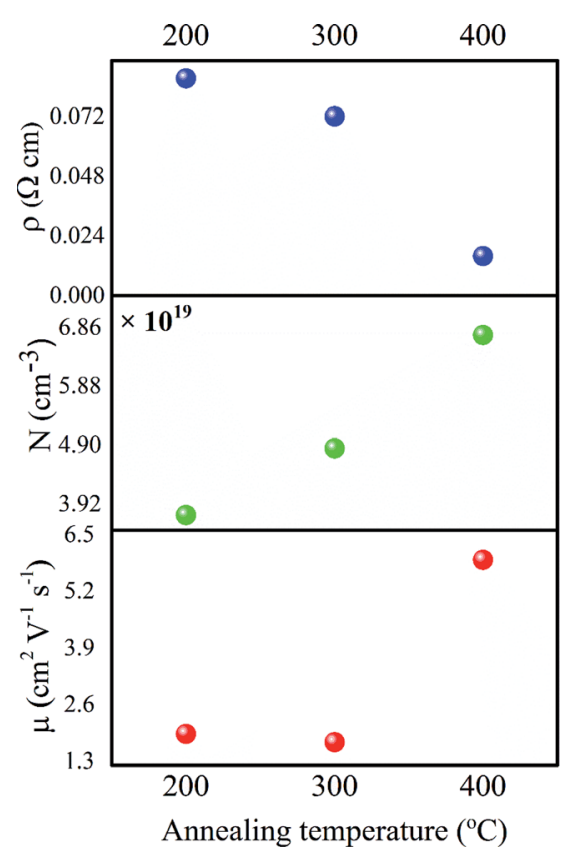

Fig. 5 Hall effect measurements of IZTO thin films annealed at three different temperatures. at $600{ }^{\circ} \mathrm{C}$ for $2 \mathrm{~h}$; it might have resulted in the insufficient oxygen interstitials to balance repulsive forces originated from doping. ${ }^{10}$. (Details of calculation of lattice parameter using Nelson Riley function and combustion synthesis of $\operatorname{In}_{2} \mathrm{O}_{3}$ powder is addressed in ESI S2 $\dagger$ ).

The minimum combustion temperature and clean burning nature of precursor with optimum $\mathrm{F}: \mathrm{O}(=0.5)$ grabbed our attention to fabricate thin film onto the glass substrate. All films annealed at different temperatures $\left(200,300\right.$ and $\left.400{ }^{\circ} \mathrm{C}\right)$ were crystalline in nature (Fig. 4a) possessing bixbyite crystal structure but, when it is compared with low temperature combustion derived powder counterpart (Fig. 2a, XRD pattern of $\mathrm{F}: \mathrm{O}=0.5$; as combusted powder) which is a mixture of both crystalline and amorphous phases. The decomposition of precursors and formation of doped oxides is different in case of thin films compared to bulk systems. In other words, combustion in a coated film has a different mechanism; because of large surface area of thin films. ${ }^{41}$ Thus it is important to study thin film materials as thin films rather than depending on their bulk counterparts. ${ }^{42}$ Although the combustion behavior on thin films is not clear, ${ }^{43}$ but the precursors having fuel-ligand (acetylacetone in this study) can yield crystalline thin films (Fig. 4a) at significantly low temperature $\left(200{ }^{\circ} \mathrm{C}\right)$, which would have not been possible with conventional sol-gel precursors ${ }^{44}$ with large decomposition temperatures $\left(>450{ }^{\circ} \mathrm{C}\right)$. Further, the film annealed at $200^{\circ} \mathrm{C}$ shows considerable degree of transparency $(83 \%)$ in the visible region (Fig. $4 \mathrm{~b}$ ) with an optical band gap of $4.2 \mathrm{eV}$ (Fig. 4b; plot (eqn (3)))

$$
\alpha h \nu=\alpha_{\mathrm{o}}\left(h \nu-E_{\mathrm{g}}\right)^{1 / 2},
$$

where $\alpha, h \nu, \alpha_{\mathrm{o}}$ and $E_{\mathrm{g}}$ are absorption coefficient, photon energy or incident energy, constant and band gap of IZTO respectively.

Further, in order to investigate the electronic properties of coated IZTO films; Hall effect measurements were carried out and found that the order of carrier concentration $(N)$ was about $10^{19} \mathrm{~cm}^{-3}$ irrespective of annealing temperature (Fig. 5). It shows an increasing trend within the range of $3.7 \times 10^{19}$ to 6.7 $\times 10^{19} \mathrm{~cm}^{-3}$; this clearly indicates the formation of vacancies contributing free charge carriers results in decrease in the 
(a)

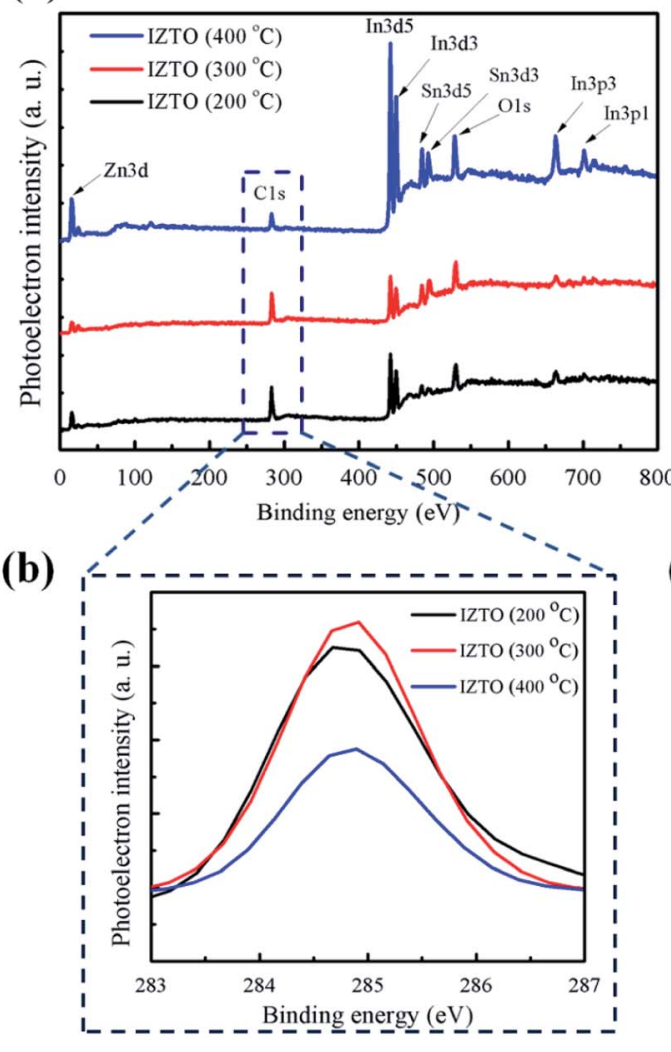

(c)

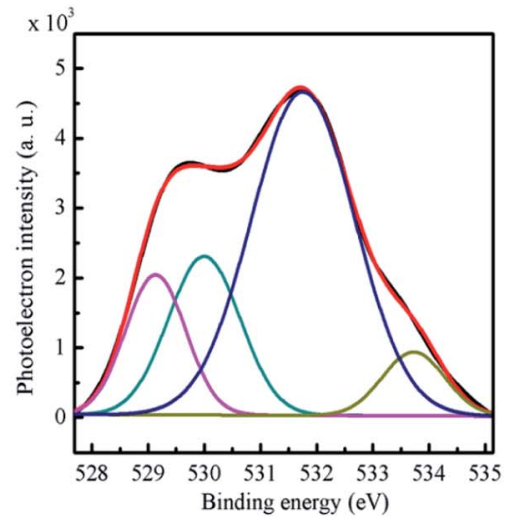

(d)

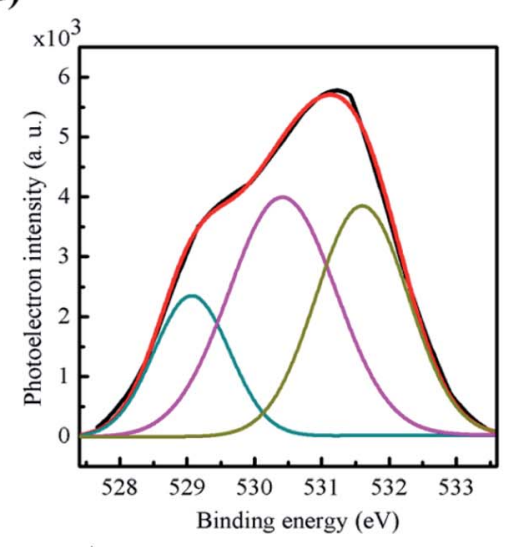

(e)

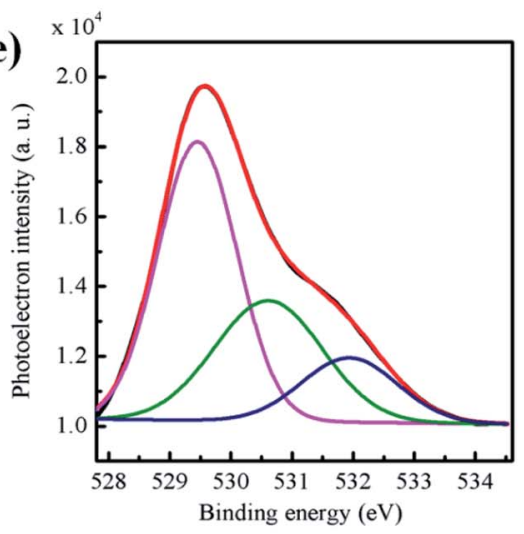

(f)



Fig. 6 (a) XPS survey scan spectra obtained for IZTO films annealed at different temperatures (b) exaggerated view of $\mathrm{C} 1 \mathrm{~s}$ signature. Deconvoluted $\mathrm{O}$ 1s peaks of IZTO annealed at (c) $200{ }^{\circ} \mathrm{C}$ (d) $300{ }^{\circ} \mathrm{C}$ and (e) $400{ }^{\circ} \mathrm{C}$; (f) the intensity ratios of $\mathrm{M}-\mathrm{O}-\mathrm{M} / \mathrm{M}-\mathrm{OH}$ and $\mathrm{M}-\mathrm{O}-\mathrm{M} / \mathrm{O}-$ adsorbates as a function of annealing temperature.

resistivity ( $\rho$ ) of the films (Fig. 5). The order of resistivity $\left(10^{-2} \Omega \mathrm{cm}\right)$ especially at $200{ }^{\circ} \mathrm{C}$ is much lower than previously reported value for combustion derived ITO thin film; $;^{35}$ the improvement in the conductivity of the films is mainly guided by free charge carriers though there is small dip in the $\mu_{\mathrm{H}}$ at $300{ }^{\circ} \mathrm{C}$ which doesn't have much effect on the overall resistivity of the IZTO at $300{ }^{\circ} \mathrm{C}$.

In order to get more insight, X-ray photoelectron spectroscopic analysis of the films were carried out (Fig. 6). The full range scans (Fig. 6a) show indium, zinc, tin, oxygen and carbon signatures; source of trapped carbonaceous impurities might have come from unburnt carbon of the fuel, apart from the fact that the balanced redox mixture leaves no traces of unburnt hydrocarbon. One interesting thing about balanced reaction is that, it doesn't really takes care of secondary reactions such as decomposition of nitrates, hydrolysis etc. resulting in the continuous variation of $\mathrm{F}: \mathrm{O}$ ratio $^{45}$ as reaction progresses; consequence of which can be seen as the left out carbon trace resulting in scattering of the carriers; Fig. $6 \mathrm{~b}$ shows exaggerated view of $\mathrm{C} 1 \mathrm{~s}$ signature depicting fluctuations in the carbon impurity at $200{ }^{\circ} \mathrm{C}$ and $300{ }^{\circ} \mathrm{C}$, but when annealed it at $400{ }^{\circ} \mathrm{C}$ is found that there is a drastic decrease in the intensity of the $\mathrm{C} 1 \mathrm{~s}$ peak thereby reducing the scattering of the carriers. This can be clearly visualized from the $\mu_{\mathrm{H}}$ results (Fig. 5), the slight decrease 

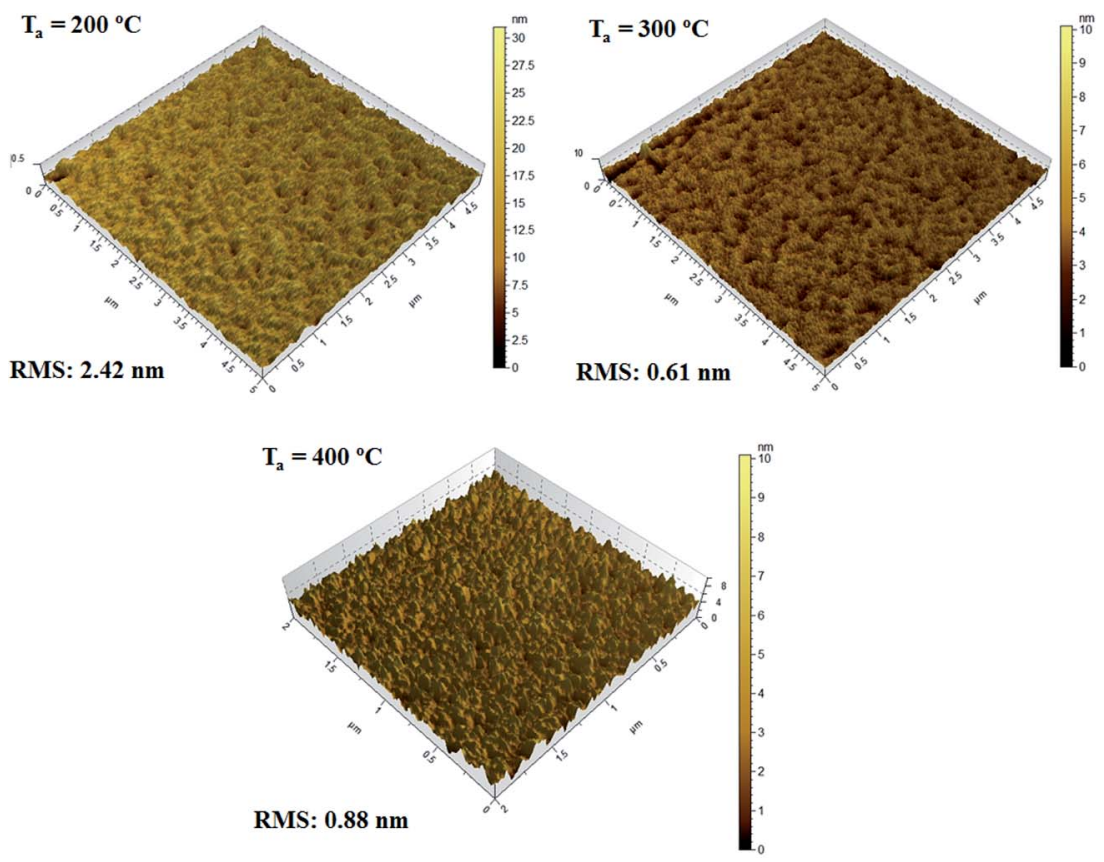

Fig. 7 AFM results of IZTO films annealed at 200,300 and $400{ }^{\circ} \mathrm{C}$.

in the value from 200 to $300{ }^{\circ} \mathrm{C}\left(1.92\right.$ to $\left.1.73 \mathrm{~cm}^{2} \mathrm{~V}^{-1} \mathrm{~s}^{-1}\right)$ is due to fluctuations in the carbonaceous impurities, but when annealed at $400{ }^{\circ} \mathrm{C}$ the reduction of carbonaceous impurity (Fig. 6b) led to the sharp shoot-up in the $\mu_{\mathrm{H}}$ from 1.73 to $5.92 \mathrm{~cm}^{2} \mathrm{~V}^{-1} \mathrm{~s}^{-1}$ (Fig. 5). Further, Fig. 6(c-e) shows deconvoluted $\mathrm{O} 1 \mathrm{~s}$ peaks of films annealed at 200,300 and $400{ }^{\circ} \mathrm{C}$ respectively; possessing principal signatures at $529 \pm 0.5 \mathrm{eV}$ corresponding $\mathrm{M}-\mathrm{O}-\mathrm{M}$ lattice, ${ }^{46} 531.5 \pm 0.5 \mathrm{eV}$ depicting bulk and surface metal hydroxide species $(\mathrm{M}-\mathrm{OH}){ }^{46} 530 \pm 0.5 \mathrm{eV}$ corresponding $\mathrm{O}$-adsorbates ${ }^{47}$ on the surface and additional signature (at $533.7 \mathrm{eV}$ (ref. 48)) in the film annealed at $200{ }^{\circ} \mathrm{C}$ was observed (Fig. 6c). The Gaussian deconvoluted peaks give clear idea of precursor transformation into desired oxide. ${ }^{49}$ The ratio of intensities of these peaks $(\mathrm{M}-\mathrm{O}-\mathrm{M} / \mathrm{M}-\mathrm{OH}$ and $\mathrm{M}-\mathrm{O}-\mathrm{M} /$ $\mathrm{O}$-adsorbates), as shown in the Fig. 6f, clearly convey the information that at low temperature the formation of $\mathrm{M}-\mathrm{O}-\mathrm{M}$

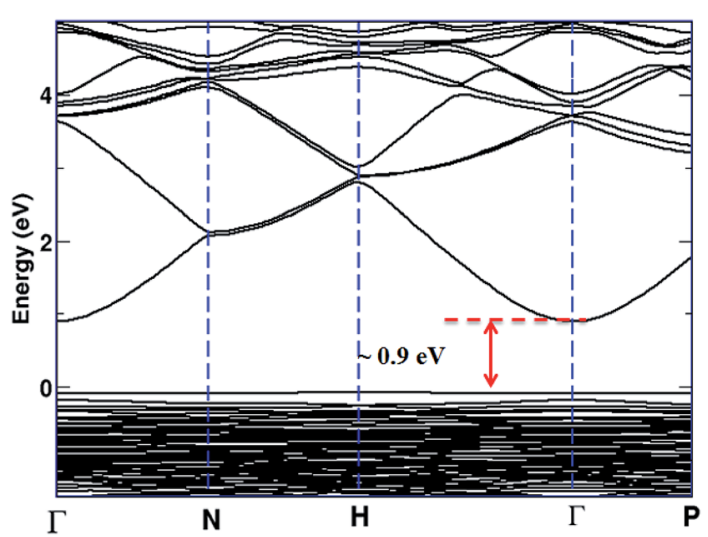

Fig. 8 Electronic band structure of IZTO showing direct band gap of $0.9 \mathrm{eV}$. lattice is less pronounced compared to high temperature annealed films where there is a drastic increase of $\mathrm{M}-\mathrm{O}-\mathrm{M} / \mathrm{M}-$ $\mathrm{OH}$ ratio from $200{ }^{\circ} \mathrm{C}$ to $400{ }^{\circ} \mathrm{C}$ can be supported by GIAXRD scans (Fig. 4a). It reflects the enhancement in the crystallinity with temperature, thus at high temperature the films are more of product oxides compared to films annealed at low temperature. The untransformed hydroxides are detrimental to the electrical performance of this film, that's the reason why the conductivity and the Hall mobility were considerably low at $200{ }^{\circ} \mathrm{C}$, compared to high temperature annealed films. Formation lattice is the key for improved electrical performance of the film in terms of both mobility and generation of free carriers which contribute to electrical conductivity.

The film annealed at $400{ }^{\circ} \mathrm{C}$ shows highest $\mathrm{M}-\mathrm{O}-\mathrm{M} / \mathrm{M}-\mathrm{OH}$ and $\mathrm{M}-\mathrm{O}-\mathrm{M} / \mathrm{M}-\mathrm{OR}$ ratios; which gives a clear evidence for the better quality of the film.

Also, the films annealed at different temperatures were smooth in nature with rms roughness below $2.42 \mathrm{~nm}$ (Fig. 7); at low temperature $\left(200{ }^{\circ} \mathrm{C}\right)$ because of incomplete oxide formation led to slightly rough surfaces (Fig. 7) but with increase in the temperature the rms roughness shows smaller and values within the acceptable range $(<1 \mathrm{~nm})$.

As we have analyzed the quality and characteristics of films fabricated at low temperature; further we want to throw some light on the reason for the conducting nature of IZTO; Fig. 8 shows the electronic band structure of IZTO constructed using first principle DFT (refer Section 2.4) calculations which shows a direct band gap of $0.9 \mathrm{eV}$ (Fig. 8). Calculated band gap is much smaller than the parent $\operatorname{In}_{2} \mathrm{O}_{3}$ band gap. ${ }^{50}$ This is mainly due to the impurity state from the doped atom present in the band gap energy region. Atom projected density of state of IZTO (ESI S3 $†$ ) clearly shows the impurity trap states from doped $\mathrm{Zn}$ and $\mathrm{Sn}$ 


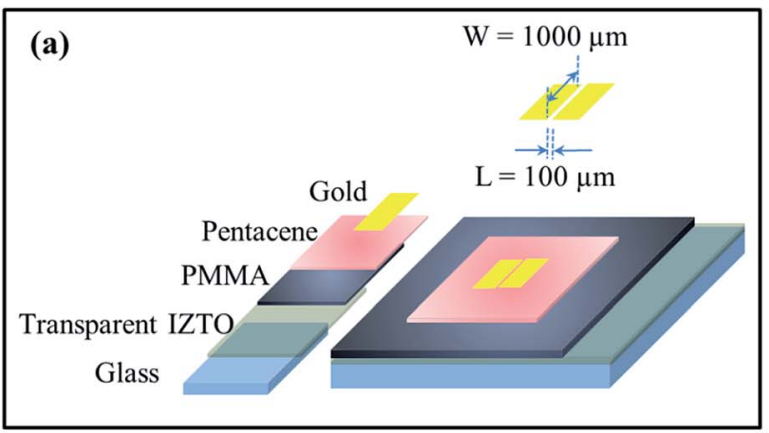

(c)

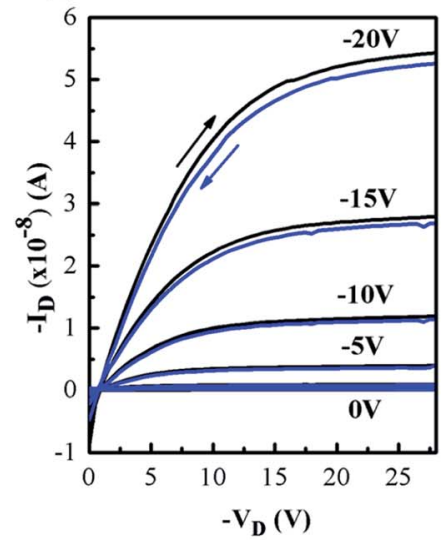

(d)

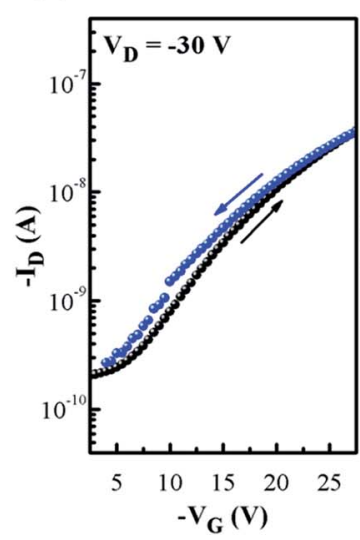

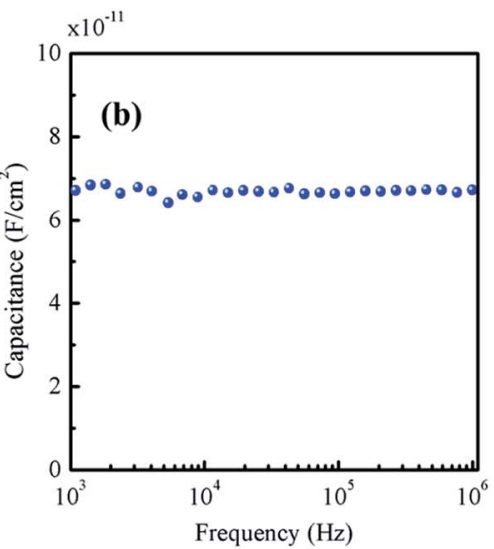

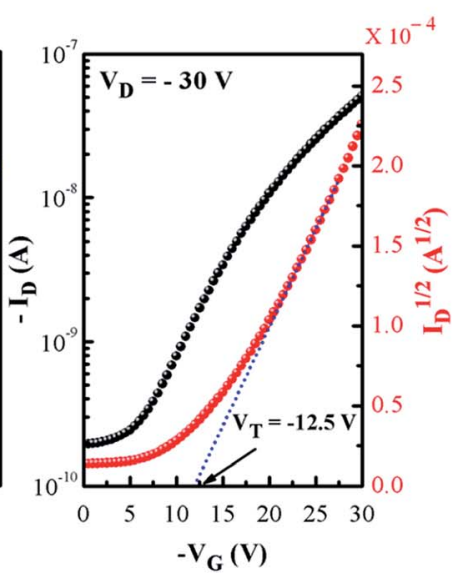

Fig. 9 (a) Bottom gate top contact architecture, (b) capacitance vs. frequency of PMMA, (c and d) output and transfer (hysteresis) characteristics of TFT.

atom are present in the energy gap region, whereas the unfilled conduction states of In are $3.8 \mathrm{eV}$ above the valence band maxima. Although optical band gap was found to be $4.2 \mathrm{eV}$ (Fig. 4b), but electron could jump easily from the trap state to conduction band by overcoming a gap of $0.9 \mathrm{eV}$, is considered to be the main cause of conduction.

Further, the IZTO film on glass annealed at $400{ }^{\circ} \mathrm{C}$ is utilized for the fabrication of TFTs with following architecture glass/

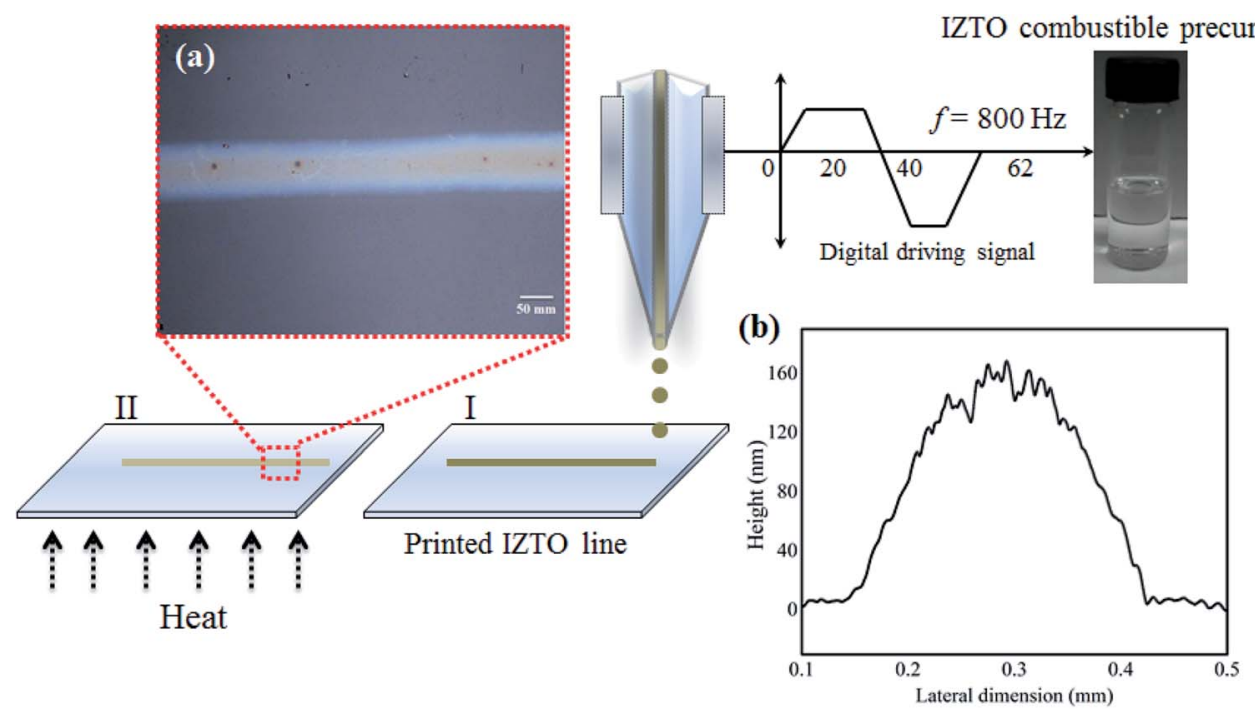

Fig. 10 Printing of IZTO combustible precursor (a) printed IZTO line (b) line profile of printed line feature. 
IZTO/PMMA/pentacene/Au, as shown in Fig. 9a. The capacitive response of PMMA dielectric as a function of frequency is illustrated in Fig. 9b. The output and transfer characteristics of TFT are as shown in the Fig. 9c and d. The electrical parameters such as $\mu_{\text {sat }}, I_{\text {on }} / I_{\text {off }}$ ratio and $V_{\mathrm{T}}$ were extracted from the transfer characteristics and determined to be $0.44 \mathrm{~cm}^{2} \mathrm{~V}^{-1} \mathrm{~s}^{-1}$ (from eqn (2)), $10^{3}$ and $-12.5 \mathrm{~V}$, respectively. In addition, the hysteresis observed in both output and transfer characteristics was minimum (Fig. 9c and d). It shows the applicability of solution combustion derived IZTO to be used as a conducting film in an optoelectronic device.

Further, when it comes to highly transparent devices such as TFTs till date the most of the work was based on usage of metal contact electrodes which are opaque in nature and the body of the contact electrode pads are blind to the visible light there by decreases the overall transparency of the device. Recently, solgel derived cadmium oxide and aluminum doped cadmium oxide were inkjet printed ${ }^{51}$ using both 2-ME and aqueous based solutions and concluded that at low temperature 2-ME based solutions result in strong coffee ring deposits depicting high degree of edge deposits; but the present 2-ME based IZTO combustible precursor shows no such effect (Fig. 10a and b). It may be due to the presence of two different organic compounds (2-ME and acetylacetone-fuel) having different surface tension added with the pre-annealing temperature of $200{ }^{\circ} \mathrm{C}$ which helps in creating sufficient surface tension gradients there by supporting Marangoni inward flow suppressing edge deposit. Thus, it's possible to get dome (Fig. 10b) shaped printed feature in 2-ME based combustible precursor also. But, still more work has to be done in this area to establish strong base for 2-ME combustible precursor based printing; here in this contribution the possibility of anti-coffee ring deposit via 2-ME based system is demonstrated; which was recently proved best for aqueous sol-gel system. ${ }^{49}$ Moving on, the pre-annealed printed line feature was then subjected to high temperature of $400{ }^{\circ} \mathrm{C}$ and found that the conductivity shows a similar value as that of $400{ }^{\circ} \mathrm{C}$ annealed films via spin coating.

\section{Conclusions}

A complex ternary conducting zinc tin co-doped indium oxide (IZTO - $\mathrm{In}_{1.4} \mathrm{Sn}_{0.3} \mathrm{Zn}_{0.3} \mathrm{O}_{3}$ ) is established in this study; solution combustion derived both bulk-powder and thin films were analyzed. In addition, initial trials of combustion reaction with varying $\mathrm{F}: \mathrm{O}$ ratios depicted an optimum $\mathrm{F}: \mathrm{O}$ derived from balanced redox mixture having minimal combustion temperature $\left(\sim 130^{\circ} \mathrm{C}\right)$ added with its clean burning behavior. Further, the film fabricated via same solution showed a decreasing trend in resistivity (of the order $10^{-2} \Omega \mathrm{cm}$ ) with annealing temperature and highest $\mu_{\mathrm{H}}$ of $5.92 \mathrm{~cm}^{2} \mathrm{~V}^{-1} \mathrm{~s}^{-1}$ at $400{ }^{\circ} \mathrm{C}$ with carrier concentration of $10^{19} \mathrm{~cm}^{-3}$ irrespective of annealing temperature. Also, the film (annealed at $200{ }^{\circ} \mathrm{C}$ ) was transparent (83\%) to the visible light; all IZTO films were smooth with rms values $2.42 \mathrm{~nm}, 0.61 \mathrm{~nm}$ and $0.8 \mathrm{~nm}$ at $200{ }^{\circ} \mathrm{C}, 300{ }^{\circ} \mathrm{C}$ and $400{ }^{\circ} \mathrm{C}$ respectively. The TFT fabricated using IZTO as one of its conducting component (gate electrode) with PMMA and pentacene as dielectric and active materials respectively has shown a $\mu_{\text {sat }}$,
$I_{\mathrm{on}}: I_{\mathrm{off}}$ and $V_{\mathrm{T}}$ of $0.44 \mathrm{~cm}^{2} \mathrm{~V}^{-1} \mathrm{~s}^{-1}, 10^{3}$ and $-12.5 \mathrm{~V}$ respectively with negligible hysteresis. Further, printability of combustion precursor was established and demonstrated the high quality of printed line feature with anti-coffee ring effect.

\section{Author contribution}

P. P., S. M., D. G. and Y. Y. N. designed experiments; K. T. developed both unit cell and band structure of IZTO; P. P. conducted experiments; S. G. and P. P. fabricated TFT and characterized; M. S. and P. P. optimized printing; B. G. and P. P. synthesized powders and analyzed. All authors read the manuscript and gave their valuable suggestions.

\section{Conflicts of interest}

There are no conflicts to declare.

\section{Acknowledgements}

This work is supported by Science and Engineering Research Board (SERB), Department of Science and Technology (DST) (ECR/2015/000339), DST - SB/S3/EECE/027/2013, DST - SB/FTP/ PS-032/2014. We acknowledge, the Department of Metallurgical and Materials Engineering; NITK-Surathkal, and Department of Metallurgical Engineering and Materials Science (MEMS)-IIT Bombay, Centre for Excellence in Nanotechnology (CEN-IIT Bombay), IRCC, NCPRE - IIT Bombay; authors also extend regards to Amit Tewari (Research Scholar, IITB-Monash), PEELIITB.

\section{References}

1 S. P. Harvey, K. R. Poeppelmeier and T. O. Mason, J. Am. Ceram. Soc., 2008, 91, 3683-3689.

2 P. E. Burrows, G. L. Graff, M. E. Gross, P. M. Martin, M.-K. Shi, M. Hall, E. Mast, C. Bonham, W. Bennett and M. B. Sullivan, Displays, 2001, 22, 65-69.

3 G. Crawford, Flexible flat panel displays, John Wiley \& Sons, 2005.

4 K. H. Choi, H. J. Nam, J. A. Jeong, S. W. Cho, H. K. Kim, J. W. Kang, D. G. Kim and W. J. Cho, Appl. Phys. Lett., 2008, 92, 223302.

5 J. H. Bae, J. M. Moon, S. W. Jeong, J. J. Kim, J. W. Kang, D. G. Kim, J. K. Kim, J. W. Park and H. K. Kim, J. Electrochem. Soc., 2008, 155, J1-J6.

6 K. H. Lee, H. W. Choi, K. H. Kim and C. W. Bark, Mol. Cryst. Liq. Cryst., 2012, 567, 78-85.

7 W. S. Cheong, US Pat. 20130266724 A1, 2012.

8 K. H. Choi, J. A. Jeong and H. K. Kim, Sol. Energy Mater. Sol. Cells, 2010, 94, 1822-1830.

9 J. H. Lee, H. S. Shin, S. I. Na and H. K. Kim, Sol. Energy Mater. Sol. Cells, 2013, 109, 192-198.

10 G. B. González, J. B. Cohen, J.-H. Hwang, T. O. Mason, J. P. Hodges and J. D. Jorgensen, J. Appl. Phys., 2001, 89, 2550-2555. 
11 Y. R. Denny, S. Seo, K. Lee, S. K. Oh, H. J. Kang, S. Heo, J. G. Chung, J. C. Lee and S. Tougaard, Mater. Res. Bull., 2015, 62, 222-231.

12 L. Raniero, I. Ferreira, A. Pimentel, A. Goncalves, P. Canhola, E. Fortunato and R. Martins, Thin Solid Films, 2006, 511, 295-298.

13 C. Lee, R. Dwivedi, W. Lee, C. Hong, W. I. Lee and H. W. Kim, J. Mater. Sci.: Mater. Electron., 2008, 19, 981-985.

14 D. E. Proffit, T. Philippe, J. D. Emery, Q. Ma, B. D. Buchholz, P. W. Voorhees, M. J. Bedzyk, R. P. Chang and T. O. Mason, J. Electroceram., 2015, 34, 167-174.

15 H. C. Ma, M. Putri, J. H. Cheon, J. H. Kim and H. Y. Lee, J. Korean Phys. Soc., 2012, 61, 1994-1999.

16 A. Ambrosini, G. Palmer, A. Maignan, K. R. Poeppelmeier, M. Lane, P. Brazis, C. Kannewurf, T. Hogan and T. O. Mason, Chem. Mater., 2002, 14, 52-57.

17 M. G. Kim, H. S. Kim, Y. G. Ha, J. He, M. G. Kanatzidis, A. Facchetti and T. J. Marks, J. Am. Chem. Soc., 2010, 132, 10352-10364.

18 T. Minami, T. Kakumu, K. Shimokawa and S. Takata, Thin Solid Films, 1998, 317, 318-321.

19 Y. Shen, D. Jacobs, G. Malliaras, G. Koley, M. Spencer and A. Ioannidis, Adv. Mater., 2001, 13, 1234-1238.

20 A. Gurlo, Nanoscale, 2011, 3, 154-165.

21 A. Gurlo, M. Ivanovskaya, N. Barsan and U. Weimar, Inorg. Chem. Commun., 2003, 6, 569-572.

22 A. Gurlo, D. Dzivenko, P. Kroll and R. Riedel, Phys. Status Solidi RRL, 2008, 2, 269-271.

23 H. Kim, C. Gilmore, A. Pique, J. Horwitz, H. Mattoussi, H. Murata, Z. Kafafi and D. Chrisey, J. Appl. Phys., 1999, 86, 6451-6461.

24 N. Bsiri, M. Zrir, A. Bardaoui and M. Bouaïcha, Ceram. Int., 2016, 42, 10599-10607.

25 S. Tabassum, E. Yamasue, H. Okumura and K. N. Ishihara, Appl. Surf. Sci., 2016, 377, 355-360.

26 Y. Choi, G. H. Kim, W. H. Jeong, H. J. Kim, B. D. Chin and J. W. Yu, Thin Solid Films, 2010, 518, 6249-6252.

27 C. Jin, I. K. You and H. K. Kim, Curr. Appl. Phys., 2013, 13, S177-S181.

28 Y. Takahashi, S. Okada, R. B. H. Tahar, K. Nakano, T. Ban and Y. Ohya, J. Non-Cryst. Solids, 1997, 218, 129-134.

29 S. R. Ramanan, Thin Solid Films, 2001, 389, 207-212.

30 S. I. Na, B. K. Yu, S. S. Kim, D. Vak, T. S. Kim, J. S. Yeo and D. Y. Kim, Sol. Energy Mater. Sol. Cells, 2010, 94, 1333-1337.

31 H. C. Huang and T. E. Hsieh, Nanotechnology, 2010, 21, 295707.

32 W. J. Park, H. S. Shin, B. Du Ahn, G. H. Kim, S. M. Lee, K. H. Kim and H. J. Kim, Appl. Phys. Lett., 2008, 93, 083508.
33 Y. Y. Noh, X. Cheng, H. Sirringhaus, J. I. Sohn, M. E. Welland and D. J. Kang, Appl. Phys. Lett., 2007, 91, 043109.

34 C. N. R. Rao, Chemical approaches to the synthesis of inorganic materials, John Wiley \& Sons Inc, 1994.

35 M. G. Kim, M. G. Kanatzidis, A. Facchetti and T. J. Marks, Nat. Mater., 2011, 10, 382-388.

36 G. Kresse and J. Furthmüller, Comput. Mater. Sci., 1996, 6, 15-50.

37 G. Kresse and J. Furthmüller, Phys. Rev. B, 1996, 54, 11169.

38 P. E. Blöchl, Phys. Rev. B, 1994, 50, 17953.

39 K. C. Patil, M. Hegde, T. Rattan and S. Aruna, Chemistry of nanocrystalline oxide materials - Combustion synthesis, properties and applications, World Scientific, New Jersey, 2008, ISBN 13 978-981-279-314-0.

40 C. Suryanarayana and M. G. Norton, X-ray diffraction: a practical approach, Springer Science \& Business Media, 2013.

41 D. Sanchez-Rodriguez, J. Farjas, P. Roura, S. Ricart, N. Mestres, X. Obradors and T. Puig, J. Phys. Chem. C, 2013, 117, 20133-20138.

42 S. R. Wood, K. N. Woods, P. N. Plassmeyer, D. A. Marsh, D. W. Johnson, C. J. Page, K. M. Jensen and D. C. Johnson, J. Am. Chem. Soc., 2017, 139, 5607-5613.

43 B. Wang, X. Yu, P. Guo, W. Huang, L. Zeng, N. Zhou, L. Chi, M. J. Bedzyk, R. P. Chang and T. J. Marks, Adv. Electron. Mater., 2016, 2, 1500427.

44 Y. H. Kang, S. Jeong, J. M. Ko, J.-Y. Lee, Y. Choi, C. Lee and S. Y. Cho, J. Mater. Chem. C, 2014, 2, 4247-4256.

45 R. Branquinho, D. Salgueiro, L. Santos, P. Barquinha, L. Pereira, R. Martins and E. Fortunato, ACS Appl. Mater. Interfaces, 2014, 6, 19592-19599.

46 J. W. Hennek, J. Smith, A. Yan, M. G. Kim, W. Zhao, V. P. Dravid, A. Facchetti and T. J. Marks, J. Am. Chem. Soc., 2013, 135, 10729-10741.

47 H. Faber, Y. H. Lin, S. R. Thomas, K. Zhao, N. Pliatsikas, M. A. McLachlan, A. Amassian, P. A. Patsalas and T. D. Anthopoulos, ACS Appl. Mater. Interfaces, 2014, 7, 782-790.

48 S. Jeong, J. Y. Lee, S. S. Lee, Y. Choi and B. H. Ryu, J. Phys. Chem. C, 2011, 115, 11773-11780.

49 M. Benwadih, R. Coppard, K. Bonrad, A. Klyszcz and D. Vuillaume, ACS Appl. Mater. Interfaces, 2016, 8, 3451334519.

50 F. Fuchs and F. Bechstedt, Phys. Rev. B, 2008, 77, 155107.

$51 \mathrm{~W}$. J. Scheideler, R. Kumar, A. R. Zeumault and V. Subramanian, Adv. Funct. Mater., 2017, 27, 1606062. 